AC 2012-3005: DEVELOPING SKEPTICAL REVERENCE FOR MATHEMATICS

Dr. Julie Gainsburg, California State University, Northridge

Julie Gainsburg is Associate Professor of secondary education at California State University, Northridge, where she has taught credential and graduate-level courses for pre-service and in-service mathematics teachers since 2003, when she earned her Ph.D. in curriculum and teacher education from Stanford University. In addition to studying mathematics-teacher development, she has studied the mathematical behavior and development of civil engineers and drawn implications for K-12 mathematics education. 


\title{
Developing Skeptical Reverence for Mathematics
}

\begin{abstract}
In a prior study of civil engineers, I identified a hybrid disposition towards mathematics that I termed skeptical reverence: a balance between seeing mathematics as an indispensible tool and understanding its limitations. The current study investigates how engineers develop their perspective on the relationship between mathematics and engineering and this disposition of skeptical reverence. Ten students (2-3 at each of the four years of an undergraduate program) and two new engineers were interviewed twice each; the students also participated in individual "think-aloud" problem-solving sessions, in which they worked on an assigned problem set from a target course and verbalized their thinking and problem-solving strategies. I used qualitativedata-analysis methods to characterize the students' mathematical dispositions and their movement towards fully developed skeptical reverence.
\end{abstract}

\section{Introduction}

A major issue in mathematics education is the tendency of students to view mathematics as an activity that only takes place in schools and is unrelated to the rest of their lives. This view is hypothesized to cause educational trouble, such as a lack of student motivation and thus less learning, and students' inability to apply what mathematics they do learn in the service of solving problems outside of school or in other subjects. Many adults have not outgrown this sense that mathematics has little utility in their everyday activity or work. Even in engineering, with its clear reputation as math intensive and its considerable requirements for mathematical training, the amount of mathematics individual engineers actually need to know in order to perform everyday work is debated, especially now that computers handle much of the computation.

In prior research ${ }^{1}$, I showed that structural engineers made daily use of mathematics. The mathematical topics they used were usually basic - taught by ninth grade, but these engineers demonstrated impressive fluency and flexibility in applying this mathematics. Accompanying this fluency was a hybrid attitude towards the role of mathematics in engineering, which I termed skeptical reverence: a balance between seeing mathematics as an indispensible tool and understanding its limitations. I argued that this disposition was functional and necessary for engineers to carry out design and analysis effectively; the wrong level of reliance on mathematics - too much reverence or too much skepticism — would incur safety and economic risks. Unanswered by this prior research was how these engineers developed their perspective on the relationship between mathematics and engineering and this disposition of skeptical reverence. This question is taken up by the study reported here.

This study was part of a larger project to investigate how engineers develop as problem solvers who apply mathematics effectively. I conjecture that a significant part of this development involves disposition - that understanding and appreciating the relationship between mathematics and engineering is crucial to learning how to use mathematics in the service of solving engineering problems. Unknown is whether this disposition is developed primarily in engineering programs or waits until employment, and how it evolves. This study was an initial 
attempt to map the development of the mathematical disposition necessary to successful engineering by examining the attitudes of people along the engineering-development continuum, from freshman year into the workplace.

Why are young engineers' beliefs about mathematics and its relationship to engineering important? A key component of the expertise of the experienced engineers I studied was their ability to use mathematics to serve their problem-solving purposes. This required a keen understanding of the powers and limitations of the formal and informal mathematical tools of their practice. Only rarely could mathematical procedures be applied wholesale (as they usually are in school); the genius of the engineer was the flexible selecting and adapting - sometimes even overriding - of mathematical procedures to model real phenomena, based on a deep understanding of the phenomena. Young engineers who see little connection between mathematics and engineering, who perhaps believe that "real engineers don't use math," would seem unlikely to learn to use the mathematics well. Yet, young engineers who view engineering as the routine application of known mathematical procedures, or who believe that mathematics serves as the ultimate authority for engineering decisions, will be equally impeded in their efforts to attain engineering expertise. Although I developed the notion of skeptical reverence based on observations of and interviews with structural engineers, it is reasonable to assume that this hybrid attitude towards mathematics and its role in real-world problem solving is instrumental to many engineering and other mathematized fields. If so, it is important to understand how students develop it.

\section{Theoretical framework}

Students' dispositions towards and beliefs about mathematics have been theorized to have significant impact on learning mathematics ${ }^{2-4}$. Various scholars have emphasized that dispositions and beliefs must be studied in order to fully understand the development of mathematical problem-solving ability ${ }^{5,6}$. Studies have shown that many K-12 and college students come to believe that mathematics is a rule-driven, linear, solitary, school-only activity, in which problems have one correct solution that should be quickly evident and where true understanding requires special talent ${ }^{4,7}$. This counterproductive view can intimidate and discourage students and filter them out of science, technology, engineering, and mathematical (STEM) fields ${ }^{2,8,9}$. Acknowledging this problem, mathematics-education reformers have made a productive mathematical disposition a deliberate goal of instruction ${ }^{10,11}$. The authors of Adding it $U p^{11}$ identified "productive disposition" as one of five strands of mathematical proficiency, describing it as "the tendency to see sense in mathematics, to perceive it as both useful and worthwhile, to believe that steady effort in learning mathematics pays off, and to see oneself as an effective learner and doer of mathematics" (p. 131).

Of particular relevance to the study reported here is the perception of the usefulness and worth of mathematics. Conventional wisdom holds that students see mathematics as a school-based practice with little connection to their out-of-school lives and that this view has negative consequences for motivation and learning quality. Some scholarship bears this out ${ }^{2,12}$, but the situation may be more complicated. In the 1996 NAEP, about $70 \%$ of $4^{\text {th }}$ and $8^{\text {th }}$ graders agreed that mathematics was useful for solving everyday problems. However, although they felt that mathematics was important to society in general, they did not necessarily believe it was 
personally important ${ }^{11}$. Adults, too, have complicated mathematical dispositions. Lave (1988) ${ }^{13}$ showed that people avoid using formal mathematics in everyday settings (for example, grocery shopping) but still resolve quantitative problems effectively, using informal, contextualized methods. Nevertheless, people subscribe to cultural claims about the "hegemony of schooltaught math over everyday practice" (p. 168) - the idea that the formal, general, algorithmic mathematics taught in schools should structure the way people resolve all quantitative problems, because it is superior to the irrational, situation-specific mathematics that people naturally invent and use. As a result, people feel guilty or inadequate for not using formal mathematics and sometimes resort to using it post hoc, to justify a solution they arrived at by informal means (for example, for the benefit of researchers).

Lave and other mathematical ethnographers ${ }^{14,15}$ studied "just plain folks" (JPFs) - people without advanced mathematical training - in settings that were not highly mathematized. It is reasonable to assume that people with high levels of mathematical education who are trained to use mathematics in STEM fields might have a different, more productive mathematical disposition than JPFs. Interestingly, however, engineers' self reports on the utility of mathematics in their work are mixed, with engineers sometimes downplaying mathematics' role in their everyday work ${ }^{16.17}$. This may be bravado on the part of engineers, but researchers have noted that workers can be blind to the mathematics that they use $\mathrm{e}^{18,19}$, in particular if they consider "using mathematics" to mean performing standard, formal, advanced mathematical procedures by hand. Even engineering educators are divided on the importance and role of mathematics education for engineers, and some question whether advanced mathematics is necessary $^{20-24}$.

A few studies characterize the mathematical beliefs of engineering students. Some studies reveal that engineering students, like K-12 students, often fail to see the importance of mathematics in their training or eventual employment ${ }^{24,25}$ and may even dislike or fear mathematics ${ }^{26}$. In contrast, perhaps because of their more extensive coursework, the senior-year engineering students surveyed by Cardella (2006) ${ }^{27}$ reported that the content and problem-solving skills they learned in their college mathematics courses were useful in their engineering classes, and they believed that mathematical ability and the ability to apply mathematics to real-world problems were very important for becoming an engineer. Yet Cardella and Atman (2004) ${ }^{28}$ noted that engineering students tend to think of their mathematics courses as providing content, not processes or practices. Engineering students sometimes believe that only the mathematical rules (not their derivation) matter, or fail to see the connections between the mathematics and underlying physical concepts ${ }^{29,30}$. Further, their understanding of key physical or engineering concepts may remain shallow and computationally focused throughout their undergraduate years. As Montfort, Brown, and Pollock (2009) ${ }^{31}$ found, students may continue to "use equations as the foundational truth of a concept" (p. 122).

Less has been written about the mathematical disposition that engineering students should develop and that successful engineers have. This is unfortunate. If we take engineers to be expert mathematics users - exemplifying the kind of mathematical application in problem solving that schools hope to promote - then their mathematical disposition would seem a potential model and goal for education. The lack of systematic research on this topic motivated my prior study of the disposition of structural engineers towards the role of mathematics in their work ${ }^{1}$. Through 
extensive observations of engineers in everyday practice and interviews, I came to characterize their mathematical disposition as one of skeptical reverence, in which mathematics is seen as a powerful and necessary tool that must be used judiciously and skeptically. This perspective is the virtual opposite of the one Lave found in JPFs, who considered mathematics hegemonic over human activity, at least for other people, but personally unhelpful. In contrast, engineers recognize mathematics in their work as subjective and fallible, not authoritative or hegemonic but integrated with and sometimes subservient to social, economic, and other contextual concerns. At the same time, the engineers I studied could not conceive of doing their work without mathematics; it was their most powerful and ubiquitous tool. Further, their work activity occurred within the context of a profession in which mathematics is the mandatory language for design and analysis, and mathematical proof the industry standard for final justification. In this last point there is some overlap between the perspectives of engineers and JPFs: Both sometimes used formal mathematics for post hoc justifications of solutions obtained by other means.

The epistemological aspect of skeptical reverence recalls the broader concept advanced by King and Kitchener (1994) ${ }^{32}$ of reflective judgment. Mainly applied to college students, reflective judgment is the endpoint of a developmental continuum corresponding to the recognition of the complexity and uncertainty of real-world problems, an awareness of the need to interpret knowledge in the context in which it was constructed (and revise it in light of new evidence), and the ability to evaluate solutions and knowledge along many criteria, including conceptual soundness, fit with evidence, utility, and efficiency. The well-documented development of students through the seven stages of epistemic cognition ${ }^{32}$ lends credence to the idea that engineering students might undergo a discipline-specific version, gradually developing an understanding of the nature of engineering problems and of what constitutes truth and knowledge in engineering.

Indeed, strongly related to the concept of skeptical reverence is that of engineering judgment, a profession-wide but ill-defined term. Engineering judgment is cited by engineers as the ultimate authority over design decisions and, consequently, over the use of mathematics ${ }^{1,33}$. The engineers I studied construed engineering expertise as the development of engineering judgment, rather than as an increased ability to apply mathematical methods. Engineering judgment draws on deep domain knowledge about physical phenomena, not on political, economic, or other more social kinds of knowledge, although these are also central to engineers' decision making. Exercising engineering judgment requires the engineer to keep mathematical procedures tied closely to physical interpretations, recalling a feature of the "street mathematics" of Brazilian street merchants studied by Nunes, Schliemann, and Carraher $(1993)^{34}$. Redish and Smith $(2008)^{30}$ elaborated on engineers' "blending of distinct local coherences: our understanding of the rules of mathematics and our sense and intuitions of the physical world" (p. 302). In contrast to a pure mathematician's view, Redish and Smith explained that for engineers:

- Equations represent relationships among physical variables, which are often empirical measurements.

- Symbols in equations carry information about the nature of the measurement beyond simply its value. This information may affect the way the equation is interpreted and used.

- Functions in science and engineering tend to stand for relations among physical 
variables, independent of the way those variables are represented....

Professional scientists and engineers typically interpret what appear on the surface to be mathematical equations as physical. There is a strong association between their mental spaces that conceptualize the physical system and the mathematical symbols that represent various measurements. (p. 302)

Thus, an important aspect of the mathematical disposition of the engineer is the perception and constant awareness of a tight relationship between mathematical procedures and physical phenomena and an appreciation of the importance of understanding and interpreting procedural steps and intermediate and final result values in terms of physical implications.

A disposition of skeptical reverence for mathematics arguably would be highly productive for students in engineering and other mathematized fields. However, it is unknown how engineers come to posses this disposition. It is unlikely to be innate, as it apparently relies on an understanding of the profession of engineering. That is, an engineer's perspective on the role of mathematics in engineering is not necessarily the same as her perspective on the role of mathematics in everyday life, which is easier to imagine someone possessing even prior to education. Likelier, a view on the role of mathematics in engineering develops during schooling, through mathematical engineering courses and learning about engineering itself, and continues to evolve once on the job. This study investigates the evolution of engineers' dispositions with a backwards approach: It rests on the assumption, grounded in my prior research, that the ultimate mathematical disposition of engineers, that of skeptical reverence, is a productive and desirable one for future engineers and other professionals. It then targets individuals at various stages of the transition between school and engineering work and explores their evolving perceptions of the relationship between mathematics and engineering.

\section{Methods}

This study focused on the 12 participants who were selected to represent early engineerdevelopment stages: two students in each of Years 1 and 2 of the undergraduate civil-engineering program at California State University, Northridge: three students in each of Years 3 and 4 in this program, some of whom also had some engineering work experience, and two recent program graduates working as new engineers. The investigation of the schooling phase centered on four core courses identified by program faculty as central to the development of the students' use of mathematics in engineering problem solving: Calculus (Year 1), Statics (Year 2), Strength of Materials (Year 3), and Reinforced Concrete Design (Year 4). These courses were targeted for observations and the solicitation of student participants, although students reported on their other courses during interviews. From the students who volunteered for the study, I selected those best representing the typical student at that point in the program in terms of prior courses, age, and work experience. Table 1 shows the participants.

I interviewed each of these participants twice: students at the beginning and end of the semester to detect growth during the target course, and new engineers about 9 months apart. The interview protocol inquired about participants' educational background in mathematics and engineering, feelings and conceptions about mathematics and its relationship to engineering and the rest of the 
"real world," their decision to become an engineer, their use of or learning about technology, and their understanding and use of mathematics in problem solving in school or at work.

Table 1: Participants

\begin{tabular}{|c|c|c|c|c|}
\hline Status & Pseudonym & Target Course & $\begin{array}{l}\text { Engineering Work } \\
\text { Experience }\end{array}$ & Other Notes \\
\hline \multirow[t]{2}{*}{ Year 1} & Ann & \multirow{2}{*}{$\begin{array}{l}\text { Calculus } \\
\left(2^{\text {nd }} \text { semester }\right)\end{array}$} & None & \\
\hline & Albert & & None & \\
\hline \multirow{2}{*}{ Year 2} & Ben & \multirow{2}{*}{ Statics } & None & \\
\hline & Bradley & & None & \\
\hline & & & & \\
\hline \multirow[b]{3}{*}{ Year 3} & Connor & \multirow{3}{*}{$\begin{array}{l}\text { Strength of } \\
\text { Materials }\end{array}$} & None & \\
\hline & Chuck & & None & \\
\hline & Claude & & 2 yrs (structural) & $\begin{array}{l}\text { Experience at construction } \\
\text { and architecture firms }\end{array}$ \\
\hline \multirow{3}{*}{ Year 4} & Doug & \multirow{3}{*}{$\begin{array}{l}\text { Reinforced } \\
\text { Concrete Design }\end{array}$} & None & \\
\hline & Daniel & & 3 yrs (land development) & \\
\hline & Dmitri & & 9 yrs (civil) & $\begin{array}{l}\text { Significant mathematical } \\
\text { training }\end{array}$ \\
\hline \multirow{2}{*}{$\begin{array}{l}\text { New } \\
\text { Engineer }\end{array}$} & Naomi & \multirow{2}{*}{ (NA) } & $1 \mathrm{yr}$ (environmental) & \\
\hline & Nicki & & $\begin{array}{l}2 \text { yrs (civil; recently rotated } \\
\text { from project management } \\
\text { to geotechnical design) }\end{array}$ & $\begin{array}{l}\text { Enrolled in MS program in } \\
\text { Civil Engineering }\end{array}$ \\
\hline
\end{tabular}

There were a few differences in the protocols for students and new engineers. The new engineers were also asked to compare problems they had solved in school to those they solved today on the job and about the difference between novice and expert engineers in their company and how that transition occurs. The students provided a second form of data: After each interview, they participated in an individual "think-aloud" problem-solving session, in which they worked on an assigned problem set from the target course and verbalized their thinking and problem-solving strategies.

As the participants in this study represented different stages in an engineering career, it was inappropriate to combine the data for general coding. Instead, I approached all data with the question, How does this participant perceive the role of mathematics in engineering? For each participant, I extracted data relevant to this question from the interview and "think-aloud" transcripts. From these extracted data, I created a narrative summary for each participant. Then I synthesized these summaries into a case narrative for the group at each stage, highlighting patterns but preserving individual differences. In the next section, I summarize my findings. 


\section{Findings summary}

\section{The engineering authenticity of mathematics courses}

In general, the students in this study valued their mathematics courses and did not recommend eliminating any, though they had mixed predictions about how much school-taught mathematics would be used in future engineering courses and work, predictions that seemed unrelated to their year in the program. Even if they did not expect many of the mathematics topics to apply, many students still viewed their mathematics classes favorably for the mental training they provided, which these students perceived as preparation for the logical, structured nature of engineering. As Ben (Year 2) said, "It's not necessarily to learn the math, like the material. It's more to, like, train your mind to think a certain way." Despite doubting that all topics seen in their mathematics courses would be relevant to their future careers, a few students essentially equated engineering and mathematics. As Connor (Year 3) put it, "You can't do engineering without math.... Engineering is math. It's just math with meaning behind the numbers.... It's a way of giving an explanation of how things work in the world."

Students who had no workplace experience were likelier to believe that the exercises they did in engineering classes replicated those they would see in the workplace. They trusted the authenticity of the assigned problems and given numerical values to the extent that they believed they could check their solutions based on their real-world reasonableness. Often these students lacked the domain knowledge to do this directly; instead, they compared their results to those of example problems from class, which they also presumed to be realistic. Only two students, Claude and Dmitri, who had the most workplace experience, observed that course-assigned problems were sometimes designed inauthentically, for pedagogical purposes. As Claude noted

When I took Dynamics, a lot of the problems were very complicated in that sense, where they added a whole bunch of elements that really made life not fun. And in the real world, sometimes engineers try to make everything as simple as possible, so we will not be adding all these crazy elements into a problem. Like, you can usually simplify things down to problems that are doable. So adding all that unnecessary complication I guess is to test you on your previous knowledge of math, but not necessarily applicable. (Claude, Year 3)

While sophisticated in the sense of being metacognitive, Claude's observation fails to acknowledge that engineers start with complicated problems, and that often the main challenge is simplifying them ${ }^{1}$; in other words, assigning students pre-simplified problems would be even less authentic. Claude's point may have been that school problems do not offer the option to simplify.

For the other students, engineering seemed to be essentially equivalent to solving mathematics problems, though some, like Daniel, understood that workplace mathematics would be less precise and involve more estimation.

A lot of teachers do say engineering is estimation. They say if you're trying to look for a specific answer, you're not in the right field!... A lot of it is based off safety factors. So, I 
mean, that safety factor compensates just to cover your butt, in a way. So if something says you can only, in an elevator, for example, says you can only apply about 5,000 pounds or so, it really means you can apply about 8,000 or so before it breaks, you know? There's a lot of leeway you can play with, as far as the design. (Daniel, Year 4)

\section{Making physical sense of mathematical procedures}

The students varied in terms of how much physical sense they could make of the problems, methods, and variables involved in their coursework. Introductory physics appeared pivotal: Many students named this course as the experience that first tied mathematics to physical phenomena and showed them the relevance and power of mathematics. But personal experience with physical phenomena was also invoked:

[The concept of moment] definitely does make sense, at least partially because of [high school] robotics [club]. Because I have turned wrenches on bolts and I know that the more perpendicular of the force you apply to the moment arm, or whatever, the stronger the force is going to be, or the stronger the moment is going to be. So that definitely does make sense. A combination of just my experience just with doing similar problems in real life, applying torques and moments, and just logic about it: Well, if I'm pressing directly along the moment arm, I know that I'm not going to be turning it either way. I could be applying a lot of pressure but not going to be doing anything. (Bradley, Year 2)

That engineering was grounded in real phenomena was valued by most of the students:

Pure math problems can be - they can get — it's hard to see the forest for the trees, I guess. You can get lost in the numbers and not understand what anything means and just be computing and plugging and plugging stuff in and really just hoping that you get the right answer, and if you don't you gotta go back and do it all over again. And now it's a lot more things that I can grasp, and quantities make more sense, especially when I have been around this stuff for a little while. So just quantities of weight, force, and reaction and those things all kind of start making more sense, whereas in math classes, they just pick numbers. [Me: Making sense meaning you have a feel for what they should be?] Yeah, what they should be, and if you get an answer and you're, like, whoa, that's not even close to what it probably should be, you can check yourself that way. But in math class, it's all randomly generated numbers usually, so there's no-you have no way of telling if you're right just by looking at the answer. (Claude, Year 3)

This variance in how much physical sense students were able to make appeared to be more due to individual attitude about the importance of independently doing this intellectual work rather than due to year in the program. During a think-aloud session, Chuck exemplified those who tried to make physical sense:

Here's the equation: Delta $L$ equals $P L$ over $A E$. Which makes sense because the longer it is, the higher the length, it'll get bigger; the bigger the pressure, the bigger the length. $E$, I can't really explain; that's very in depth. And $A$ is the cross-sectional area. So if you look at the cross-sectional area, I guess, if it's bigger and you pull it won't stretch as much, as 
opposed to if you have something thinner, and you pull, it'll stretch more. [Me: So you're explaining why $P$ and $L$ are on the top - ] And $A E$ are in the bottom, why that makes sense. [Me: Had you gone through that thinking before, or are you just doing that now for the first time?] I'd done it before. Every time I see an equation, I try to think of it, so if I forget it, I could always come back to it. (Chuck, Year 3)

Even the students most motivated to make physical sense of the concepts could be stymied by the more abstract concepts and were then reduced to trust. When asked what sense Chuck made of the concept of Mohr's Circle (a graphical representation of the state of stress on a point on a body, in which the $x$-coordinate represents normal stress and the $y$-coordinate shear stress), he admitted

[The instructor] didn't show us how it came about, but I trust that it looks like it works! So, to answer your question, yes it makes-No, it doesn't make sense, 'cause I don't know how it came about but, yeah, it makes sense as in it works, so I trust it. (Chuck, Year 3)

Some complained about limited time to make this kind of sense. Asked how hard he tried to relate statics concepts to physical phenomena, Ben replied, "Sometimes I do wonder about it, but I have so much other stuff to do, there's just no time to really think about that. I mean, it works, so-_." Similarly, Dmitri, after working out a problem, reported:

I just feel fuzzy about [my solution] because I don't feel like I spent the time to really understand what everything stands for... I'd want to think what a term represents to make sure I'm not skewing any units, make sure I have like quantities, and referring to everything by proper terminology. So I think: force to force, strain to strain, stress to stress, square inches to square inches, that sort of thing. (Dmitri, Year 4)

Doug and Daniel, in contrast, focused on the procedural nature of engineering, rather than physical meaning. This view of engineering was evident in Doug's work on the think-aloud problems, which he deemed easy because he could follow a given procedure: "It was basically like reading a book, almost, like you just follow the story." When asked whether a particular variable had physical meaning for him, Doug replied with a chuckle, "No, not at all. To be honest, most of this I don't have a physical sense." He based his confidence in his solving on his ability to follow the given procedure and the nearness of his results to those of class examples, and he caught one error by the latter means. Daniel, with three years of experience in a landdevelopment firm, also perceived engineering as being highly structured and "cookbook"- - he even expected design to be "cookbook" once he had more experience with it; by implication, he saw mathematics as a means to carry out established engineering algorithms. Daniel dismissed the instructor's real-world references during lectures as unimportant tangents to the "real" stuff of the course:

[Year 4 Instructor] is very structured. I mean, he does go off on tangents talking about engineering stuff but I guess he covers the material that we need to know. [Me: When you say structured, I'm not sure what you mean.] When he's presenting the material, it's very organized how he presents it, like, in a logical fashion, and makes sure we get it. [Me: 
Those tangents: Are they really tangents? Do they do anything for you?] Related to the class? No! [Laughing] I think they're just pretty much talking, conversation! (Daniel, Year 4)

Several students noted that computers in the workplace would perform many of the mathematical routines they were now being taught to do by hand, but they parroted their instructors' admonitions against blindly trusting computer output. Some students saw mathematical proficiency as a route to an understanding of the concepts underlying the computer programs that would prevent blind use and errors.

Building a building is not like stacking a bunch of Lego's together, you know, just in a bigger form. There's a lot of things taken into consideration. And [students] can't really understand that unless they actually take the math courses that apply to those things... Even if I'm not going to apply [mathematics], and I know for a fact that many engineers don't — and it's not that they don't want to, it's that the jobs don't require them to; everything's on the computers - I think it's important to know, have an actual understanding of what you're doing, even if the computer's doing it for you. It's important to have an actual understanding of what's going on, because if there's mistake you can intuitively see it. (Connor, Year 3)

Yet it was not always clear whether the concepts of which the students spoke were mathematical or engineering concepts, or whether these students even saw a clear difference. Asked why engineering students are required to take many mathematics courses, Daniel replied:

I guess it's to understand the concepts, where they come from. Like, the background. Most of our equations are derived from it, so I guess we've got to know the theory before we actually apply it. [Me: When you say understand the concepts: Mathematical concepts? Engineering concepts?] Mathematical concepts. [Me: So they make you take math to understand the mathematical concepts?] Right. And then engineering is based on that, for the most part, so I would say a lot of our equations that we use are derived from the basics. (Daniel, Year 4)

\section{Subjectivity and the primacy of domain knowledge}

Only two students, Chuck and Dmitri, articulated the subjectivity inherent in the role of mathematics in engineering. For Chuck, this had come as a recent revelation:

Everyone thinks engineering is a science. But then [Year 3 instructor] goes, "It's an art!" I never thought of it like that. And then when you think of it like that, it opens up a whole new realm of, like, thinking about engineering. It's like, wow, this is pretty cool. [Me: What do you think he means when he says that?] Well, he said you can manipulate the problem any way to make it get results that you want. So in that sense, and in the sense of, um, it's just, well [long pause] - It's art in the way that you're building something and you have to make it work. (Chuck, Year 3) 
Dmitri was also one of only two students (with Connor, Year 3) to express an understanding of the primacy of domain knowledge in engineering problem solving. Dmitri, with nine years in an engineering firm, frequently found himself able to perform the mathematical aspects of problem solving in his workplace but lacking other knowledge - about code and zoning requirements, what types of devices existed and which would work in a given situation, and costs - that he needed to solve complete problems independently. He observed that, in school, "legalities and economics go out of the window, but those two end up being the driving forces in actual design," and without fluency in these, he found himself "floundering" at work. Indeed, Dmitri had observed engineers using mathematics post hoc, as a means to "prove" their designs. He saw this mathematical ability setting the engineer apart from drafters and contractors, who could accomplish most of the same design tasks from experience but perhaps not as quickly or safely as the engineer:

An engineer is someone who can build for 50 cents what anyone can build for a dollar. [Me: And math is the difference?] Yeah. Because the alternative is to spend $\$ 1.50$ or \$2.00 to build a dollar model and that doesn't work, to build a 25-cent model that falls apart, and then, oh, the 50-cent model, that works. And that's the minimum that doesThat's a whole lot more expenditure when you're talking about actual construction than to sit down ahead of time and say, based on what I know, I can show that under these conditions, this is the 50-cent model that we should build. It comes down to saving money and saving lives. (Dmitri, Year 4)

\section{New Engineers}

In general, the new engineers had similar views to the students. One notable difference was the new engineers' somewhat deflated view of the use of mathematics in everyday engineering, at least as manifested in their current jobs. While disappointing, this view had not tarnished their appreciation for mathematics and approval of mathematics courses. They saw the latter as instrumental for supporting the learning of key engineering concepts. They also echoed the students' notion that mathematics courses promoted "mental training" in the ways of thinking that were important for engineers, to which Nicki added a recruitment rationale:

The pure applied math doesn't help me in my job today. But I wouldn't not have that information. Like, I wouldn't have wanted to not have gone through that. I think that it separates-it's like a filtering process. Like, are you smart enough to get through the math so that you can actually become an engineer? Same with the physics. Are you smart enough to get through the physics? Are you smart enough to get through the chemistry? Are you able to get through those core curriculum in order to see that you have the capability to solve these real-world problems? (Nicki, New Engineer)

A year or two into their careers, however, they had not yet witnessed the kind of flexible and powerful use of mathematics that I observed in veteran engineers, nor had they been exposed to the skepticism that accompanied this use. Still, Nicki sensed that something was missing; she felt she was not yet doing real engineering because there was no mathematical challenge to her work. 


\section{Discussion}

This study has significant limitations and can only be considered an exploratory step towards mapping the development of individual engineers' understanding of the relationship between mathematics and engineering. The small number of participants, of course, does not represent all students at each stage, nor can this single program represent all of undergraduate engineering education (although it is probably typical of programs at large, regional campuses). Indeed, the variation among the two or three participants at each stage of this study portends broad diversity in the larger population. At best, this study begins to paint a picture of the transition from highschool student, with little conception of the usefulness of mathematics, to veteran engineer, with an attitude of skeptical reverence towards mathematics. Also, this study reifies and attends to an aspect of engineering education that is generally overlooked and left to develop automatically; more explicit attention to this transition may permit educators and mentors to speed or enhance it. Finally, this study clarifies what further research would enable painting the picture in greater detail and understanding how to positively impact the development of skeptical reverence.

In general, I found engineering students and new engineers optimistic about the value of mathematics education for their careers, while somewhat unclear on the reason. This optimism may extend back before college, which might indicate that K-12 students who intend careers in engineering have more positive attitudes towards mathematics than their peers. Most participants claimed to have liked mathematics or at least have been good at it prior to college, which alone would distinguish them from many K-12 students. Conversely, it is possible that the move from high school to undergraduate engineering program causes an immediate shift in their perspective on mathematics. Such is suggested by the students' remarkable trust in the authenticity of the exercises assigned in their engineering classes and even college calculus - a belief that the numerical values and the solving processes reflect real engineering work. Despite the fact that these exercises (to me) resembled the word problems in a high-school mathematics textbook, the students overestimated their authenticity, seemingly reversing many high-school students' underestimation of the utility of secondary-level mathematics. What explains this sudden perspective shift? One possibility may be that the students view the engineering program as preprofessional, vocational - a hybrid stage between school and work, with instructors who live in both the college and engineering worlds. Whereas high school offered no association with a specific career or group of professionals (other than teachers), the engineering program may feel like an early stage of professional participation, with instructors playing the roles of mentors and gatekeepers into the profession. An area for further study would be to compare the mathematical dispositions of high-school students who intend to enter engineering (or other STEM fields) with those who do not, to help understand whether a positive attitude towards mathematics is more the cause or the result of entering a college engineering program.

While heartening, the optimism these participants displayed towards mathematics fell short of, or was vaguer than, the reverence that experienced engineers hold. Seeing some of the mathematics they had learned in school being applied in engineering contexts gave the students faith that most of the rest of it would eventually be applied, too. Especially for those with no engineering-work experience, however, their notion of mathematics' role was to support the cookbook, algorithmic problem solving that they believed engineering comprised, a view that was hardly disturbed in later years in the program. In this sense, these students seemed to exemplify the earlier, "pre- 
reflective" stages on King and Kitchener's (1994) ${ }^{32}$ continuum, where students "do not distinguish between well- and ill-structured problems, viewing all problems as though they were defined with a high degree of certainty and completeness" (p. 16). Students and new engineers expressed the sense that mathematics was scaffolding for engineering concepts and processesscaffolding that was necessary during school but could fall away once on the job, where the engineering concepts and processes could stand without active mathematical support (often because a computer would do the computation). In addition, the students valued mathematics education for the general mental training and discipline they felt it provided. To them, engineering-problem solving and mathematical-problem solving felt similar - both were logical, sequential, and algorithmic. In this respect, these students differed from those studied by Cardella and Atman ${ }^{28}$, who did not view their mathematics courses as providing processes or practices. The idea that mathematics education offers general mental training has been historically pervasive ${ }^{35}$, observed across college students ${ }^{36}$, and even attributed to veteran engineers $^{37}$ despite their recognition that their work is far from algorithmic. That studying mathematics increases general reasoning ability, however, has been challenged by neuropsychological evidence ${ }^{35,38}$ as well as situated-cognition theories ${ }^{39}$.

In general, these engineering students' positive dispositions towards mathematics would surely seem productive in terms of motivating mathematics learning, but they hardly capture the challenging, flexible, and open-ended uses of mathematics required of practicing civil engineers. Nor do they acknowledge the central and essential role of domain knowledge, which enables the broader judgments and decisions to which the mathematical methods are subordinate. And if the students had not attained the mathematical reverence held by veteran engineers, they were even further from veterans' mathematical skepticism. Most students expressed little recognition of the limitations and subjectivity of mathematical methods in engineering and of the challenging decisions and exercise of judgment that would be required when solving quantitative problems in practice. The exception was Dmitri, with his extensive mathematical training and workplace experience. Further research could explore whether (and what kind of) work experience is responsible for the development of this skepticism, and whether it can be instilled in school. Much of the subjectivity and limitation of mathematical methods arises in the context of the mathematical modeling of physical phenomena, but modeling was outside these students' sphere of awareness (see Gainsburg ${ }^{40}$ for further discussion of this topic). Without explicit attention to mathematical modeling and its role in engineering work, it would seem difficult to develop an appropriately skeptical disposition towards mathematics' role in engineering.

\section{References}

1. Gainsburg, J. (2007). The mathematical disposition of structural engineers. The Journal for Research in Mathematics Education, 38(5), 477-506.

2. Boaler, J. (1997). Experiencing school mathematics: Teaching styles, sex, and setting. Philadelphia: Open University Press.

3. Ginsburg, H. P., \& Asmussen, K. A. (1988). Hot mathematics. In G. B. Saxe \& M. Gearhart (Eds.), Children's mathematics (pp. 89-111). San Francisco: Jossey-Bass. 
4. Schoenfeld, A. H. (1992). Learning to think mathematically: Problem solving, metacognition, and sense making in mathematics. In D. A. Grouws (Ed.), Handbook of research on mathematics teaching and learning (pp. 33471). New York: Macmillan Publishing.

5. Lesh, R., \& Zawojewski, J. (2007). Problem solving and modeling. In F. K. Lester, Jr. (Ed.), Second handbook of research on mathematics teaching and learning (pp. 763-804). Reston, VA: National Council of Teachers of Mathematics.

6. McLeod, D. B. (1992). Research on affect in mathematics education: A reconceptualization. In D. A. Grouws (Ed.), Handbook of research on mathematics teaching and learning (pp. 575-96). New York: Macmillan Publishing Company.

7. Lampert, M. (1990). When the problem is not the question and the solution is not the answer: Mathematical knowing and teaching. American Educational Research Journal, 27, 29-63.

8. Burton, L. (1999). Exploring and reporting upon the content and diversity of mathematicians' views and practices. For the Learning of Mathematics, 19(2), 36-8.

9. Cockcroft, W. H. (1982). Mathematics counts: Report of the committee of inquiry into the teaching of mathematics in schools. London: The Stationary Office (HMSO).

10. National Council of Teachers of Mathematics [NCTM]. (1991). Professional standards for teaching mathematics. Reston, VA: Author.

11. National Research Council [NRC]. (2001). Adding it up: Helping children learn mathematics. J. Kilpatrick, J. Swafford \& B. Findell (Eds.). Mathematics Learning Study Committee, Center for Education, Division of Behavioral and Social Sciences and Education. Washington, DC: National Academy Press.

12. Niss, M. (1987). Applications and modeling in the mathematics curriculum-state and trends. International Journal of Mathematics Education in Science and Technology, 18(4), 487-505.

13. Lave, J. (1988). Cognition in practice: Mind, mathematics, and culture in everyday life. New York: Cambridge University Press.

14. de la Rocha, O. (1985). The reorganization of arithmetic practice in the kitchen. Anthropology and Education Quarterly, 16, 193-8.

15. Scribner, S. (1984). Studying working intelligence. In B. Rogoff \& J. Lave (Eds.), Everyday cognition: Its development in social context (pp. 9-40). Cambridge, MA: Harvard University Press.

16. Bissell, C. \& Dillon, C. (2000). Telling tales: Models, stories, and meanings. For the Learning of Mathematics, 20(3), 3-11.

17. Kent, P., \& Noss, R. (2002). The mathematical components of engineering expertise: The relationship between doing and understanding mathematics. Paper submitted to the Institution of Electrical Engineers Annual Symposium on Engineering Education, London, January, 2002.

18. Hoyles, C., Noss, R., \& Pozzi, S. (2001). Proportional reasoning in nursing practice. Journal for Research in Mathematics Education, 32, 4-27.

19. Smith, J. P. (2002). Everyday mathematical activity in automobile production work. In M. Brenner \& J. Moschkovich (Eds.), Everyday and academic mathematics in the classroom (pp. 111-30). Reston, VA: National Council of Teachers of Mathematics. 
20. Bissell, C.C. (1996). Revitalising the engineering curriculum. Engineering Science and Education Journal, 5(3), 129-36.

21. Croft, A. C., Hibberd, S., Lawson, D. A., Mustoe, L. R., \& Shaw, C. T. (2000). Engineering mathematics in the UK: SARTOR - a timely opportunity for reform. Engineering Science and Education Journal, 9(2), 77-87.

22. Habash, R. W. Y., Suurtaam, C., Yagoub, M. C. E., Kara, K., \& Ibrahim, G. (2006). Online learning resource for smooth transition from high school to engineering education. Turkish Journal of Electrical Engineering and Computer Science, 14(1), 101-12.

23. Pearson, R. W. (1991). Why don't most engineers use undergraduate mathematics in their professional work? Undergraduate Mathematics Education Trends, 3(4), 8.

24. Simons, F. (1988). Teaching first-year students. In A. G. Howson, J-P. Kahane, P. Lauginie, \& E. de Turckheim (Eds.), Mathematics as a service subject (pp. 35-44). Cambridge, UK: Cambridge University Press.

25. Varsavsky, C. (1995). The design of the mathematics curriculum for engineers: A joint venture of the mathematics department and the engineering faculty. European Journal of Engineering Education, 20(3), 3415.

26. Otung, I. E. (2001). Reassessing the mathematics content of engineering education. Engineering Science and Education Journal, 10(4), 130-8.

27. Cardella, M. E. (2006). Engineering mathematics: An investigation of students' mathematical thinking from a cognitive engineering perspective. Doctoral dissertation, University of Washington.

28. Cardella, M. E. \& Atman, C. J. (2004). A qualitative study of the role of mathematics in engineering capstone design projects. Proceedings of the 2004 International Conference on Engineering Education, Gainesville, FL.

29. Gupta, A., \& Elby, A. (2011). Beyond epistemological deficits: Dynamic explanations of engineering students' difficulties with mathematical sense-making. International Journal of Science Education, 33(18), 2463-88.

30. Redish, E. F., \& K.A. Smith. (2008). Looking beyond content: Skill development for engineers. Journal of Engineering Education, 97(3), 295-307.

31. Montfort, D., Brown, S., \& Pollock, D. (2009). An investigation of students' conceptual understanding in related sophomore to graduate-level engineering and mechanics courses. Journal of Engineering Education, 98(2), 111-29.

32. King, P. M., \& Kitchener, K. S. (1994). Developing reflective judgment: Understanding and promoting intellectual growth and critical thinking in adolescents and adults. San Francisco: Jossey-Bass Publishers.

33. Petroski, H. (1994). Design paradigms: Case histories of error and judgment in engineering. New York: Cambridge University Press.

34. Nunes, T., Schliemann, A. D., \& Carraher, D. W. (1993). Street mathematics and school mathematics. New York: Cambridge University Press.

35. Huckstep, P. (2007). Elevate or relegate? The relative importance of mathematics. Cambridge Journal of Education, 37(3), 427-39.

36. Lin, Y-G. (1982). College students' attitudes toward mathematics. Perceptual and Motor Skills, 54, 460-2.

37. Howson, A. G., Kahane, J-P., Lauginie, P., \& de Turckheim, E. (1988). On the teaching of mathematics as a service subject. In A. G. Howson, J-P. Kahane, P. Lauginie, \& E. de Turckheim (Eds.), Mathematics as a Service Subject (pp. 1-19). Cambridge, UK: Cambridge University Press. 
38. Butterworth, B. (1999). The mathematical brain. London: Macmillan.

39. Greeno, J. (1997). On claims that answer the wrong questions. Educational Researcher, 26(1), 5-17.

40. Gainsburg, J. (2012). Learning to model in engineering. Manuscript submitted for publication.

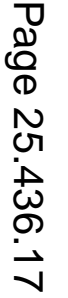

